[NOTES AND DISCUSSION]

\title{
GENITIVE SUBJECT LICENSING IN MODERN URDU
}

\author{
HiDEKI MAKI and AMANULlah BHUTTO \\ Gifu University and Islamabad College for Boys G-6/3*
}

Keywords: gender, genitive, number, subject, Urdu

\section{Introduction}

This paper examines the distribution of genitive subject in Modern Urdu (Urdu, hereafter), and investigates what its properties suggest for the theory of (Urdu) syntax. To be specific, we will argue that genitive subject licensing in Urdu provides visible evidence for the D-licensing approach proposed by Miyagawa (1993) and Maki and Uchibori (2008), among others. One of the implications of the proposed analysis is that the operation Agree (Chomsky (2000)) involved in genitive subject licensing by D in Urdu is not constrained by the Phase-Impenetrability Condition (PIC) (Chomsky (2000)), which in turn supports Bošković's (2007) claim that Agree is free from mechanisms constraining Move, such as the PIC.

The organization of this paper is as follows. Section 2 provides basic syntactic properties of Urdu in 2.1, and reviews two major approaches to genitive subject licensing in Japanese in 2.2 as the background to the subsequent sections. Section 3 presents the data on the distribution of genitive subject in Urdu. Section 4 discusses what the data may suggest for the theory of (Urdu) syntax. Finally, Section 5 concludes the paper.

* This is a drastically revised version of the paper presented at the Fifth International Spring Forum by the English Linguistic Society of Japan held at Konan University on April 22, 2012. We would like to thank the audience of the forum, Jessica Dunton, Shosuke Haraguchi, Megumi Hasebe, Fumikazu Niinuma, Reiko Okabe, Michael Sevier, and two anonymous EL reviewers for their helpful comments on an earlier version of this paper. All errors are our own. 


\section{Background}

\subsection{Basic Syntactic Properties of Urdu}

Urdu is a dialect of the Hindi-Urdu or Hindustani language, and belongs to the Indo-European family. It is the national language of Pakistan. This subsection describes basic properties of clausal structures and the case system in Urdu as the background to the subsequent sections.

First, Urdu is an ergative-absolutive language. An ergative-absolutive language maintains a syntactic or morphological equivalence for the object of a transitive verb and the single argument of an intransitive verb, while treating the agent of a transitive verb differently. Consider the examples in $(1 \mathrm{a}, \mathrm{b}){ }^{1}$

$$
\begin{aligned}
& \text { a. John-ø/*-ne yahan ponhcha. } \\
& \text { John-Abs/-Erg here arrived } \\
& \text { 'John arrived here.' }
\end{aligned}
$$

b. John-ne/*-ø kitab-ø khareedi.

John-Erg/-Abs book-Abs bought

'John bought the book yesterday.'

In (1a), the subject of the intransitive verb bears no morphological case marker. In this paper, we assume that the morphologically null case marker is the absolutive case marker, which we represent as $-\varnothing$. On the other hand, in (1b), the subject of the transitive verb is marked with the ergative case marker -ne '-Erg.' Note that the object of the transitive verb is marked absolutive, just like the subject of the intransitive verb in (1a).

Second, Urdu shows gender/number/person agreement between the subject and the predicate, as shown in (2).

(2) a. Woh John-ko rozana dekhti-hai/dekhta-hai. she/he John-to everyday see.3.SG.F/see.3.SG.M 'She/He sees John everyday.'

b. Woh John-ko rozana dekhte-hain. they John-to everyday see.3.PL

'They see John everyday.'

Third, Urdu has two types of relative clauses. Kachru (1978), among

1 The abbreviations used in this paper are as follows. 3=3rd person, Abs=Absolutive, Erg=Ergative, $\mathrm{F}=$ feminine, Gen=Genitive, INF=infinitival, $\mathrm{M}=$ masculine, Nom=Nominative, $\mathrm{NTR}=$ neutral, $\mathrm{PERF}=$ perfective, $\mathrm{PL}=$ plural, $\mathrm{PRES}=$ present, $\mathrm{RP}=$ relative pronoun, $\mathrm{SG}=$ singular, and Top=Topic. 
others, investigates relative clauses in Urdu, focusing on those with the relative pronoun starting with the $[j]$ sound, as shown in (3).

(3) Jo kitab [John-ne kal khareedi] buhut dilchasp hai.

RP book John-Erg yesterday bought very interesting be.PRES

'The book which John bought yesterday is very interesting.'

We call the postnominal relative clause the "English type" relative clause in this paper. In (3), jo functions as a relative pronoun, which cannot be deleted, as shown by the ungrammaticality of (4).

(4) *Kitab [John-ne kal khareedi] buhut dilchasp hai. book John-Erg yesterday bought very interesting be.PRES (intended reading) 'The book which John bought yesterday is very interesting.'

There is another type of relative clauses in Urdu, which do not make use of a relative pronoun, as shown in (5).

(5) [Kal John-ki khareedi-hui] kitab buhut dilchasp hai. yesterday John-Gen bought-PERF book very interesting be.PRES 'The book which John bought yesterday is very interesting.'

We call the prenominal relative clause the "Japanese type" relative clause in this paper.

Before examining Urdu relative clause data in detail, we will review two major approaches to genitive subject licensing in Japanese in the next subsection, as it will provide a useful background to the analysis of genitive subject licensing in Urdu.

2.2. Two Major Approaches to Genitive Subject Licensing in Japanese

Two major approaches have been proposed in terms of what licenses genitive subject: (a) the D-licensing approach by Miyagawa (1993), Ochi (2001), and Maki and Uchibori (2008), among others, and (b) the C-licensing approach by Watanabe (1996) and Hiraiwa (2001), among others. In this paper, for expository purposes only, we take Maki and Uchibori (2008) as a representative case of the D-licensing approach, and Hiraiwa (2001) as a representative case of the C-licensing approach.

Maki and Uchibori (2008), following the essential claim by Miyagawa (1993), propose that D licenses genitive subject in relative clauses such as (6).

(6) [Kanzenni kizu-ga/-no naotta] neko-wa kono neko desu. completely injury-Nom/-Gen cured cat-Top this cat be 'The cat which was completely cured of the injury is this cat.'

In (6), the genitive subject is preceded by an adverb, which guarantees that 
it is within the relative clause in overt syntax. Maki and Uchibori (2008) claim that D that syntactically selects NP (neko 'cat' in this case) licenses the genitive subject via Agree (Chomsky (2000)), which does not undergo LF movement to DP SPEC at LF, unlike Miyagawa (1993).

Hiraiwa (2001) proposes the C-licensing approach to genitive subject licensing, essentially following another important previous study by Watanabe (1996), which provides an insight that cross-linguistic observation is useful in elucidating the nature of genitive subject licensing. Hiraiwa observes that genitive subjects are broadly found in relative clauses in many other languages, such as Cuzco Quechua (Quechua), Chamorro (Austronesian), Turkish (Altaic), and so on. Hiraiwa then argues that genitive subject licensing in Japanese depends on the adnominal form of the verb, not D, by showing that there is a set of clauses allowing genitive subjects that do not involve a noun, such as (7), where made 'until' is not nominal in nature.

(7) John-wa [ame-ga/-no yam-u] made ofisu-ni ita.

John-Top rain-Nom/-Gen stop-PRES until office-at was

'John was at his office until it stopped raining.'

Based on Chomsky's (2000) theory of Agree, Hiraiwa (2001) proposes that while the inflection with the conclusive form of the verb corresponds to the $\mathrm{T}-(v)-\mathrm{V}$ amalgamate created via Agree in syntax, the inflection with the adnominal form of the verb results from an Agree relation of T, $(v), \mathrm{V}$, and a special type of $\mathrm{C}\left(\mathrm{C}_{\mathrm{affix}}\right.$ in Hiraiwa's terms). Hiraiwa hypothesizes that $\mathrm{C}$ in Japanese relative clauses is null and affixal, which requires an Agree relation with the $\mathrm{T}-(v)-\mathrm{V}$ to circumvent the situation where it is left stranded. He then proposes that genitive subject is licensed by the C-T- $(v)-$ $\mathrm{V}$ amalgamate, not $\mathrm{D}$, while nominative subject is licensed by the T- $(v)-\mathrm{V}$ amalgamate. Therefore, the example in (7) is grammatical in spite of the fact that the relative clause is not followed by an overt nominal element, as the genitive subject is licensed by the C-T- $(v)-\mathrm{V}$ amalgamate.

\section{Data}

Let us now examine the distribution of genitive subject in relative clauses in Urdu. First, in Japanese type relative clauses, the subject can only be marked genitive, as shown in (8).

(8) [Kal John*-ne/-ki khareedi-hui] kitab buhut dilchasp yesterday John-Erg/-Gen bought-PERF book very interesting hai.

be.PRES 
'The book which John bought yesterday is very interesting.'

On the other hand, in English type relative clauses, the subject must be marked ergative, not genitive, as shown in (9).

(9) Jo kitab [John-ne/*-ki kal khareedi] buhut dilchasp

RP book John-Erg/-Gen yesterday bought very interesting hai.

be.PRES

'The book which John bought yesterday is very interesting.'

Note here that the genitive subject in (8) is marked with the genitive case marker $-k i$ or $-k a$, depending on the gender and number of the head noun. Consider the example in (10).

(10) [Kal John-ka khareeda-hua $]$ ghora buhut dilchasp yesterday John-Gen bought-PERF horse very interesting hai.

be.PRES

'The horse which John bought yesterday is very interesting.' In (10), the head noun is ghora 'horse,' which is a masculine and singular noun, and the genitive subject is marked with $-k a$. On the other hand, in (8), the head noun is kitab 'book,' which is a feminine and singular noun, so that the genitive subject is marked with $-k i$. This is parallel to the genitive case marker on possessor nouns, as shown in (11).
a. Mary-ki
beti
Mary-Gen.F.SG daughter.F.SG
'Mary's daughter'
b. Mary-ka
beta
Mary-Gen.M.SG son.M.SG
'Mary's son'

$(11 \mathrm{a}, \mathrm{b})$ show that the possessor noun must bear $-k i$ when the head noun is feminine and singular, and it must bear $-k a$ when the head noun is masculine and singular.

A closer examination shows that the gender and number features are all shared by the head noun, the genitive subject, and the prenominal predicate, as shown in (12).

(12) [Kal John-ke khareede-hue $]$ ghore ache yesterday John-Gen.M.PL bought-PERF.M.PL horse.M.PL fine hain.

be.PRES.PL

'The horses which John bought yesterday are fine.'

Therefore, with any gender/number mismatch, the example in (13) will be- 
come ungrammatical, as shown in (14).

(13)

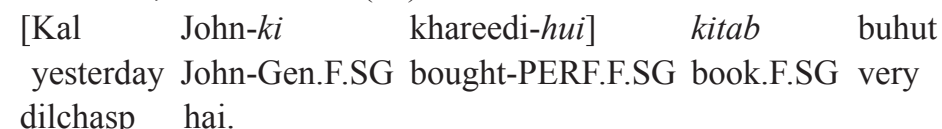
interesting be.PRES

'The book which John bought yesterday is very interesting.'

*[Kal John-ka/-ke khareedi-hui $]$ kitab
yesterday John-Gen.M.SG/-Gen.PL bought-PERF.F.SG book.F.SG
buhut dilchasp hai.
very interesting be.PRES
(intended reading) 'The book which John bought yesterday is very interesting.'

Second, genitive subject is marked with the gender-neutral genitive case marker -ke in certain contexts, as shown in (15)-(17).

(15) [Mary-ke ghar wapis aane] tak John-ø apne dafter Mary-Gen.NTR home return.INF until John-Abs his office main tha.

in be.PAST

'John was at his office until Mary returned home.'

(16)

[Train-se John-ke Tokyo jane]-ka din-ø

train-by John-Gen.NTR Tokyo go.INF-Gen.M.SG day.M.SG-Abs acha tha.

fine be.PAST

'The day when John went to Tokyo by train was fine.'

(17)

[Kal John-ke Mary-se baat karne]-ki
yesterday John-Gen.NTR Mary-to talk.INF-Gen.F.SG
jagah-ø library hai.
place.F.SG-Abs library be.PRES

'The place where John talked to Mary yesterday is the library.'

In (15), the genitive subject is marked gender-neural, and appears in a clause that does not involve a nominal head. Note that the postposition tak 'until' is not nominal in nature. In (16), the genitive subject is marked gender-neural, and appears in a clause headed by a masculine noun. Likewise, in (17), it appears in a clause headed by a feminine noun. Also, in $(15)-(17)$, the verbs are infinitival. Therefore, the generalization seems to be that gender-neutral genitive subject co-occurs with infinitival verbs.

Third, the relative pronoun jo is allowed to appear in Japanese-type relative clauses, as shown in (18). 
(18)

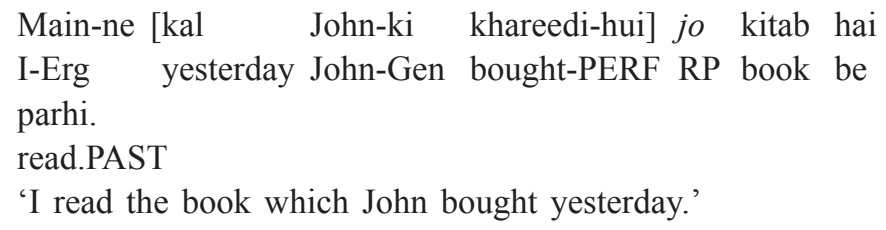

'I read the book which John bought yesterday.'

In this structure, the relative pronoun jo must co-occur with a non-main verb hai 'be' right after the head noun. Note that without the non-main verb hai 'be' or the relative pronoun jo, the example in (18) becomes ungrammatical.

\section{Discussion}

Let us now consider what the above facts may suggest for the theory of (Urdu) syntax. First, the Urdu data suggest that genitive subject in Urdu be licensed by the head noun/D. This is because in Japanese type relative clauses, the gender and number features are all shared by the head noun, the genitive subject, and the prenominal predicate, as shown by the example in (13), reproduced as (19).

(19) $[$ Kal John-ki khareedi-hui $]$ kitab buhut yesterday John-Gen.F.SG bought-PERF.F.SG book.F.SG very dilchasp hai. interesting be.PRES 'The book which John bought yesterday is very interesting.'

In (19), the head noun kitab 'book' is feminine and singular, and these features are in agreement with those in the subject and the predicate in the relative clause, in spite of the fact that the subject John is masculine. Since the subject is in agreement with the verb in gender, number, and person, as shown in (2a), reproduced as (20),

(20) Woh John-ko rozana dekhti-hai/dekhta-hai. she/he John-to everyday see.3.SG.F/see.3.SG.M

'She/He sees John everyday.'

we propose that genitive subject licensing takes place in two steps, as shown in (21).

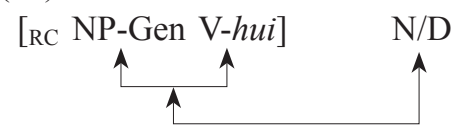

In (21), agreement takes place (i) between the subject and the verb within the relative clause, and (ii) between the relevant features on them (gender 
and number) and those on N/D.

What is important with (19) is the fact that the subject-verb agreement in gender and number is overridden by the agreement in gender and number between the head noun on the one hand, and the subject and the verb in the relative clause on the other. This in turn suggests that genitive subject in Japanese type relative clauses is configurationally accessible to, and thus, is associated with, the head noun of the relative clause in terms of Agree. Therefore, the genitive subject licensing data in Urdu provides visible evidence for the D-licensing approach originally proposed based on Japanese data, which, however, show no visible agreement between genitive subject and the outer N/D.

Second, the Urdu data suggest that not only nominal heads of relative clauses, but also infinitival verbs license genitive subjects in the language. Remember that in (15), for example, reproduced as (22), genitive subjects are possible within the clause headed by tak 'until,' which is not nominal in nature.

(22) $\quad$ Mary-k

ghar wapis aane] tak John-ø apne dafter Mary-Gen.NTR home return.INF until John-Abs his office main tha.

in be.PAST

'John was at his office until Mary returned home.'

At first sight, this fact seems to provide direct support to Hiraiwa's (2001) C-licensing approach. However, examples such as $(23 \mathrm{a}, \mathrm{b})$ show that infinitival verbs in the language can function as (verbal) nouns, which in turn lends support to Maki and Uchibori's (2008) D-licensing approach in the sense that genitive subject licensing requires nominal expressions.
a. Tokyo jana-ø mushkil hai.
Tokyo go.INF-Abs difficult be.PRES
'Going to Tokyo is difficult.'
b. Mary-se baat karna- $\varnothing$ mushkil hai.
Mary-to talk.INF-Abs difficult be.PRES
'Talking to Mary is difficult.'

The infinitival verbs in $(23 \mathrm{a}, \mathrm{b})$ are gerundive, which suggests that they function as (verbal) nouns. What is important here is the fact that the genitive subject in (22) is gender-neutral. This is precisely predicted by the fact that the infinitival form of a verb is gender-free. This also provides a straightforward account for the fact that the genitive subjects in (16) and (17) are also gender-neutral, in spite of the fact that the nominal heads of the relative clauses are either masculine or feminine. Therefore, genitive 
subject licensing in clauses with infinitival verbs involves a clause-internal agreement relationship, as shown in (24).

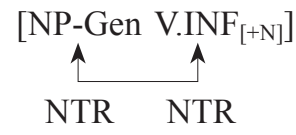

$(\mathrm{N} / \mathrm{D})$

F or $\mathrm{M}$

In (24), the infinitival verb is a (verbal) noun, and as it has no particular gender, it should be gender-neutral. Therefore, agreement between the (verbal) noun and the genitive subject results in the situation where the genitive subject is marked with the gender-neutral genitive case marker $-k e .^{2}$

Interestingly enough, while the genitive subject in (22) can only be marked gender-neutral, the subject in (16) can be marked with the masculine genitive case marker $-k a$, and the subject in (17) can be marked with the feminine genitive case marker -ki. The latter two examples are shown in (25) and (26).

Train-se John- $k a \quad$ Tokyo jane-ka din
train-by John-Gen.M.SG Tokyo go.INF-Gen.M.SG day.M.SG
acha tha
fine be.PAST
'The day when John went to Tokyo by train was fine.'
Kal John-ki Mary-se baat karne-ki jagah
yesterday John-Gen.F.SG Mary-to talk.INF-Gen.F.SG place.F.SG
library hai.
library be.PRES
'The place where John talked to Mary yesterday is the library.'

It seems natural that in (22), the subject Mary 'Mary' in the tak 'until' clause can only be marked gender-neutral, as there is no nominal element within the clause which could be associated with the genitive subject except the infinitival verb. A closer examination of the examples in (16) and (17) and those in (25) and (26) shows that there is a clear difference in meaning between them: while the relative clauses in (16) and (17) simply imply the

\footnotetext{
2 Note that the mechanism in (24) seems to support both Hiraiwa's (2001) C-licensing approach and Maki and Uchibori's (2008) D-licensing approach, because genitive subjects are licensed (i) by the C-T- $(v)-\mathrm{V}$ amalgamate within the relative clause, and (ii) by the infinitival verb which functions as a (verbal) noun. However, while the two approaches overlap in certain cases, the C-licensing approach cannot provide a straightforward account for the agreement relationship between genitive subject and the head noun of the relative clause, which the D-licensing approach can do. Therefore, we claim that the Urdu data receive a consistent analysis under the D-licensing approach.
} 
situations in which the events expressed by the relative clauses took place, the relative clauses in (25) and (26) stress the actions by the subjects. That is, only when the action by the subject is stressed can it be marked with the genitive case marker that is in agreement with the head noun of the relative clause. We thus propose that genitive subject licensing in this case takes place in two steps, just as in (21), as shown in (27).

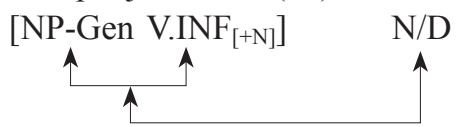

In (27), agreement takes place (i) between the subject and the infinitival verb within the relative clause, and (ii) between the relevant features on them (gender and number) and those on N/D. Therefore, (25) and (26) provide additional visible evidence for the D-licensing approach.

A note is in order here for the genitive marker that attaches to the infinitival verbs in (16), (17), (25) and (26). While it attaches to the infinitival verbs in these examples, it does not attach to the infinitival verb followed by tak 'until' in (22), suggesting that only nouns, not postpositions, induce attachment of the genitive marker to the preceding nominal expressions. Now, (25) and (26) pose no problem, because the genitive subjects, the genitive markers, and the head nouns are all in agreement in gender and number. However, (16) and (17) seem to pose a problem, as the genitive subjects are marked gender-neutral, while the gender of genitive markers and the head nouns agree. We stated above that the genitive subjects in these examples are marked gender-neutral, because the infinitival verbs are also gender-neutral. This then results in an apparent contradiction. Remember, however, that while the relative clauses in (16) and (17) simply imply the situations in which the events expressed by the relative clauses took place, the relative clauses in (25) and (26) stress the actions by the subjects. We thus assume that this semantic factor somehow prevents the genitive marker attached to the infinitival verb from affecting the genderneutral agreement relationship established between the genitive subject and the infinitival verb.

Let us now consider what the proposed analysis may imply for the theory of grammar. If the above argument is correct, it implies, given examples such as (18), reproduced as (28), that the operation Agree (Chomsky (2000)) is not constrained by the Phase-Impenetrability Condition (PIC) (Chomsky (2000)) shown in (29), which in turn provides additional support to Bošković's (2007) view that the locality of Move and Agree is radically different in the sense that Agree is free from mechanisms constraining Move, 
such as the PIC.

(28) Main-ne [kal John-ki khareedi-hui] jo kitab hai

I-Erg yesterday John-Gen bought-PERF RP book be

parhi.

read.PAST

'I read the book which John bought yesterday.'

(29) Phase-Impenetrability Condition (PIC)

In phase $\alpha$ with head $\mathrm{H}$, the domain of $\mathrm{H}$ is not accessible to operations outside $\alpha$, only $\mathrm{H}$ and its edge are accessible to such operations.

(Chomsky (2000: 108))

In the following discussion, we assume that $\mathrm{CP}$ is a phase, ignoring $v \mathrm{P}$.

In (28), the relative clause is accompanied by the relative pronoun jo, which is placed right before the head noun. Therefore, it is plausible to assume that the relative clause in (28) is characterized as CP under the assumption that a relative clause with a relative pronoun is $\mathrm{CP}^{3}$ Then, genitive subject licensing via D in terms of Agree in Urdu looks like (30).

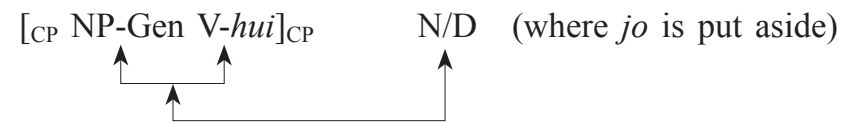

In (30), the agreement relationship between D and the genitive subject crosses a CP boundary in violation of the PIC. This fact constitutes additional evidence for Bošković (2007), who argues, contra Chomsky (2000), that the locality of Move and Agree is radically different in the sense that Agree is free from the PIC, by showing that a number of languages allow Agree dependencies that clearly violate the PIC, such as Chukchee and Blackfoot, among others.

3 One may claim that the relative pronoun jo is in $\mathrm{C}$ in overt syntax. However, this may not be so clear, given the fact that it is placed before the head noun in the English type relative clause in (3), reproduced as (i).

(i) Jo kitab [John-ne kal khareedi] buhut dilchasp hai. RP book John-Erg yesterday bought very interesting be.PRES 'The book which John bought yesterday is very interesting.'

In (i), the relative pronoun does not follow the head noun, unlike English, and they seem to constitute a unit at the surface level. In the Japanese type relative clause in (28), too, the relative pronoun and the head noun seem to constitute a unit at the surface level, just as in (i), although there is a possibility that it is actually placed in COMP. Therefore, in this paper, we put aside the question of where the relative pronoun jo is exactly located in overt syntax, and only assume that the relative clause with jo is $\mathrm{CP}$ in Urdu. 


\section{Conclusion}

In this paper, we investigated the properties of relative clauses in Urdu, and showed that there are two types of relative clauses in the language, namely, the English type postnominal relative clause and the Japanese type prenominal relative clause. Based on the prenominal relative clause data, we argued that genitive subject licensing in Urdu constitutes visible evidence for the D-licensing approach originally proposed by Miyagawa (1993). We then argued that one of the implications of the proposed analysis is that Agree is not subject to the Phase-Impenetrability Condition (PIC) (Chomsky (2000)), which in turn provides additional support to Bošković's (2007) original claim.

\section{REFERENCES}

Bošković, Željko (2007) "On the Locality and Motivation of Move and Agree: An Even More Minimal Theory," Linguistic Inquiry 38, 589-644.

Chomsky, Noam (2000) "Minimalist Inquiries: The Framework," Step by Step: Essays on Minimalist Syntax in Honor of Howard Lasnik, ed. by Roger Martin, David Michaels and Juan Uriagereka, 89-155, MIT Press, Cambridge, MA.

Hiraiwa, Ken (2001) "On Nominative-Genitive Conversion," MIT Working Papers in Linguistics 39: A View from Building E39, ed. by Elena Guerzoni and Ora Matushansky, 66-123.

Kachru, Yamuna (1978) "On Relative Clause Formation in Hindu-Urdu," Linguistics 207, 5-26.

Maki, Hideki and Asako Uchibori (2008) "Ga/No Conversion," The Oxford Handbook of Japanese Linguistics, ed. by Shigeru Miyagawa and Mamoru Saito, 192-216, Oxford University Press, Oxford.

Miyagawa, Shigeru (1993) "Case-Checking and Minimal Link Condition," MIT Working Papers in Linguistics 19: Papers on Case and Agreement II, ed. by Colin Phillips, 213-254.

Ochi, Masao (2001) "Move F and Ga/No Conversion in Japanese," Journal of East Asian Linguistics 10, 247-286.

Watanabe, Akira (1996) "Nominative-Genitive Conversion and Agreement in Japanese: A Cross-Linguistic Perspective," Journal of East Asian Linguistics 5, 373-410.

[received September 18 2012, revised and accepted January 24 2013] 
(Hideki Maki)

Faculty of Regional Studies

Gifu University

1-1 Yanagido, Gifu 501-1193

e-mail: makijp@gifu-u.ac.jp

(Amanullah Bhutto)

Islamabad College for Boys

Sector G-6/3

Islamabad, Post Code 44000

Pakistan

e-mail: amanbhutto@gmail.com 